\title{
The Biogeochemical Principles of Vernadsky as the Basis for a New Field of Science - Biospherics
}

\author{
Nickolay S. Pechurkin* \\ Institute of Biophysics of Siberian Branch of Russian Academy of Science \\ Akademgorodok, Krasnoyarsk, 660036 Russia ${ }^{1}$
}

Received 26.08.2008, received in revised form 2.09.2008, accepted 9.09.2008

\begin{abstract}
The use of the biogeochemical principles of V.I. Vernadsky for quantitative description oflife development are discussed in the paper. Two examples were examined. First the so-called «Darwin-Vernadsky paradox» connected with the complicated hierarchical structure of ecosystems and the biosphere. The second example is connected with the more qualitative than quantitative character of Vernadsky's biogeochemical principles of the biosphere and ecosystems development. Quantitative criteria to evaluate the development of multi-organismic systems need to account for energy fluxes and their use in biosystems of different hierarchical levels. Some energy criteria (principles) were presented and analyzed: EPED - Energy Principle of Extensive Development; EPID - Energy Principle of Intensive Development; MUC - Main Universal (generalized) Criterion. The two first principles are mainly connected with the behavior (development and evolution) of multi-organismic systems, belonging to the lower levels of bio-hierarchy, population/community levels. The third functional principleMUC-deals with the behavior of more complicated multi-organismic systems of the higher levels of bio-hierarchy, including ecosystems, biomes and the biosphere as a whole. The main characteristics of Biospherics as a new field of natural science are presented and discussed: 1) to create working models of the Earth's biosphere and its ecosystems; 2) to create artificial biospheres for human life support beyond the limits of the Earth's biosphere; 3) to create ground-based life-support systems that provide a high quality of life in the extreme conditions of the Earth's biosphere; 4) to use artificial ecological systems to offer the prospects of developing technologies for the solution of pollution problems.
\end{abstract}

Key words: Biosphere, Vernadsky, Biospherics, energy

\section{Introduction}

Extensive studies of the biosphere were done by Russian academician, Vladimir Vernadsky, during the first half of the 20th century. He developed and used «empirical generalizations» based on myriad observations of different researchers, along with his own comparisons and reflections (Vernadsky, 1926, 1929, 1986, 1989, 2004). But his generalized biogeochemical principles of biosphere and ecosystem development have a more qualitative than quantitative nature. To quantify Vernadsky's «empirical generalizations» for the evaluation of ecosystems and biosphere development, it is necessary to take into account energy fluxes and their use in multi-organismic systems of different hierarchical levels. (Pechurkin, 2005; Pechurkin, Shirobokova, 2001; 2003). Biological

* Corresponding author E-mail address: nsla@akadem.ru

(C) Siberian Federal University. All rights reserved 
hierarchy is one of the pervasive features of life organization on our planet. Sometimes, it is not a simple task to properly understand the interactions of the links of different hierarchical levels, as well as their stable coordinated coexistence over long periods of time. The «Darwin - Vernadsky paradox» (multiplication on the levels of organisms and populations, but adaptation on the level of the ecosystem demands) illustrates some difficulties in our interpretation of the problem. (Pechurkin, Shirobokova, 2001; Pechurkin, Somova, 2008).

\section{General discussion}

\subsection{Goals and main features of Biospherics}

Modern civilization has to develop studies in the field of Biospherics for a number of urgent reasons (Allen, Nelson, 1989; Pechurkin, 1994):

1. To create working models of the Earth's biosphere and its ecosystems and thus to better understand the regularities and laws that control its life. This is especially important because the Earth's biosphere is presently under ecological stress on a global scale.

2. To create artificial biospheres for human life support beyond the limits of the Earth's biosphere. These are essential for permanent human presence in space.

3. To create ground-based life-support systems that provide a high quality of life in the extreme conditions of the Earth's biosphere, as at polar latitudes, deserts, mountains, under water, etc.

4. To use artificial ecological systems to offer the prospects of developing technologies for the solution of pollution problems in our urban areas and for developing high yield sustainable agriculture.

By definition, this new complex scientific discipline, Biospherics, studies biotic cycles (both in experiments and in mathematical models) of different degrees of material closure and complexity. One of the practical motivations to create systems which are substantially materially isolated from the general environment of Earth is to learn how to make life support systems and artificial biospheres which can regenerate, reuse, and recycle the air, water, and food normally provided by the Earth's biosphere and by its natural recycling «cells» - ecosystems (Allen, Nelson, 1989). Here we enumerate some features of Biospherics, distinguishing it from other scientific areas (Pechurkin, 1994). The first distinction is experimental work with biotic and physical - chemical cycles or with their elements. Second feature is connected with the primary of the investigations of the functions (biotic turnover, trophic interactions of links) of natural and artificial ecosystems and their internal structures. The third feature of Biospherics is based on considerations of the hierarchical levels of multi-organismic systems. Biospherics is connected with the extensive studies of the biosphere by Russian academician Vladimir Vernadsky. He developed and used an «empirical generalizations» approach based on innumerable observations, comparisons and reflections.

\subsection{Darwin - Vernadsky paradox}

The Darwin - Vernadsky paradox is a «reverberation» of the complicated hierarchical structure of ecosystems and the biosphere. There are different ways to classify multi-organismic systems according to their biological hierarchy. Here, we can take into account, at least, four integrated hierarchical levels (Pechurkin, Shirobokova, 2001, 2003): 1) organism level (as basal one); 2) population/community level, 3) ecosystem level, as a level with cycling; 4) Biosphere level as a level of super system.

At population/community level every system seeks to exponential propagation and multiplication (according to the Darwinian - 
Maltusian law). They are necessarily open systems. But all of them to survive must be included into higher systems with cycling (biotic turnover) which trends to be closed, and is therefore more stable (according to the biogeochemical principles of Vernadsky). Also, multiplication, natural selection and evolution take place at the level of population/community. But at the level of the higher systems with biotic turnover there is no coordinated coherent inheritance, and the complicated cycle is not able to evolve as a single whole. It means that the biotic turnover differs from the organism as a single whole with its own inheritance. This is a serious flaw of the "Gaia hypothesis", for the biosphere is not a self-reproducing single organism: its components reproduce themselves). Maybe, in this sense, small artificial ecosystems made by man can be a new instrument for direct studies of the Darwin - Vernadsky paradox, and will advance our understanding: how the biotic turnover at the ecosystem level «manages» the behavior of the open elements at the population/ community level. Ecosystems can «juggle» its links, manipulating and replacing them according to biotic cycling rules (Kovda, 1975; Odum, 1983; Bartsev, 2003).

We can formulate a rule, as a kind of empirical generalization: the stability of a biotic system increases with increasing numbers of levels of multi-organismic systems, including the biosphere. This means that the biosphere (as the highest level cycle) is the most resistant to the external effects of the environment. The essence of this elevated stability is the ability to replace its elements even at the ecosystem or biome level. For example, a large long-term impact on biosphere will lead to replacement of some ecosystems or biomes. Prior to that, the ecosystem would have replaced some trophic chains (links), which would, in turn, have their populations and organisms replaced. A «bothering» portion of the human population can be replaced rather early at the population level.

\subsection{Energy Principles (criteria) of multi- organism systems' development}

The most general quantitative characteristics of systems belonging to different hierarchical levels are connected with their energy flow utilization.

2.3.1. First functional criterion - Energy Principle of Extensive Development (EPED). This energy criterion for maintenance, development and evolution of multi-organismic systems is mainly developed for application at the population/ community level (Pechurkin, 1994). One of its formulations is the energy flow, used by multiorganism biosystem, increases in the course of its development (self-development), reaching maximum local values in steady states. EPED characterizes the increase of the energy flow used by the system without qualitative changes of its structure, for example, during the increasing of population/community number. We can say that EPED manifests in processes of simple multiplication, capture of new territory and ecological succession. This energy principle is based on increased acquisition of energy in the form of organic matter for heterotrophic populations and in the form of solar energy fluxes for populations of phototrophic organisms. (For chemo-auto-trophic organisms, there are sources of energy in the form of the salts of some elements).

\subsubsection{Second functional criterion - Energy} Principle of Intensive Development (EPID). This criterion states any living system of multiorganismic levels develops(self-develops, evolves) such that the energy flow used per biological structure unit increases. EPID is the characteristic of the increase of energy flow used by system in connection with «high-qualitative», new developed changes of its structure, metabolism or behavior. For example, this can be more complete 
utilization of the limiting substrate connected with mutational changes in metabolic pathways. Or, it can be connected with the invention of new, more effective ways of collective hunting in populations of higher predators, etc. EPID, connected with new qualitative changes of the system, can be related to both microevolution and macroevolution processes.

As for biological macroevolution of animals, the increase of the energy flow used by every unit of biomass (EPID coefficient) directly corresponds with the main progressive line of macroevolution: fishes - amphibious - reptiles mammals and birds.

We can add that EPID can be also used as a Criterion of Effectiveness of Functioning for different kind of materially-open complex systems with external energy fluxes, or for special type of structure which ensures the fulfillment of its functioning (Pechurkin, Somova, 2008).

\subsubsection{Third functional principle - Main} Universal (generalized) Criterion (MUC). The two first principles are mainly connected with the behavior (development and evolution) of multi-organismic systems, belonging to the lower levels of bio-hierarchy, population/community levels. The third functional principle - MUC deals with the behavior of more complicated multi-organismic systems of the higher levels of bio-hierarchy, including ecosystems, biomes and the biosphere as a whole. At these levels, we need to consider both the external flow of free energy which induces the development of the biosystem and biochemical transformation (rotation) of limiting substances, their biotic cycling. The MUC can be formulated as follows: every multi-organismic biosystem which has cycling ( ecosystem, biome, the biosphere as a whole) develops (self-develops, evolves, emerges) to increase the ratio of free energy flow used by the system to the total mass of the limiting life (or biogenic) element.

\subsection{Comparison of Vernadsky's «biogeochemical} principles» with the quantitative criteria

Using a hierarchical approach for studies of multi-organismic systems, we can compare the above-discussed quantitative criteria with Vernadsky's «biogeochemical principles» which are more qualitative rather than quantitative descriptions. Comparison of Vernadsky's «biogeochemical principles» and quantitative criteria, using a bio-hierarchical approach, is shown in Table 1.

\section{Conclusions}

Only some «empirical generalizations» directly connected with energy - matter transformation are presented here. V.I. Vernadsky considered the energy transformation of sun rays as a inalienable property of living matter, its function in biosphere (italics of Vernadsky) (Vernadsky, 2004 , p. 58). V.I. Vernadsky wrote that «the biosphere can be considered as a part of earth's crust occupied with transformers converting space radiations into acting earth's energy electrical, chemical, mechanical, thermal, and so on» (Vernadsky, 2004, p. 43). He also emphasized that «the natural processes of living matter in their display in biosphere increase the free energy of biosphere (Vernadsky, 2004, p. 453).

In conclusion, quantitative criteria for the estimation of multi-organismic system functioning and Vernadsky's «biogeochemical principles» are of high importance for the development of Biospherics. They are needed for its theoretical considerations and for applications for Earth and Space needs. To develop a new integrated knowledge of multi-organismic system functioning, including biosphere humanity interactions, is the real challenge for our time. The necessity of it was predicted by the Russian pioneer of the science of the biosphere, V.I. Vernadsky. He foresaw the emergence of the «Noosphere», a sphere of intelligence, which 
Table 1. Comparison of Vernadsky’s «biogeochemical principles» and quantitative criteria, using bio-hierarchical approach

\begin{tabular}{|c|c|c|}
\hline $\begin{array}{c}\text { Essence of Vernadsky's } \\
\text { «biogeochemical principles» }\end{array}$ & $\begin{array}{c}\text { Main points } \\
\text { of «empirical generalizations» } \\
\text { and levels of bio-hierarchy }\end{array}$ & $\begin{array}{c}\text { Functional } \\
\text { quantitative criteria }\end{array}$ \\
\hline $\begin{array}{l}\text { 1. Wide-spread expansion of life, } \\
\text { «all over» propagation of life on } \\
\text { the surface of the Earth }\end{array}$ & $\begin{array}{l}\text { 1. Multiplication, capture of new terri- } \\
\text { and aqua-tory; population «explosion», } \\
\text { trend of humanity to Space; (low levels of } \\
\text { bio-hierarchy of multi-organism systems) }\end{array}$ & $\begin{array}{l}\text { 1. EPED - Energy Principle of } \\
\text { Extensive Development } \\
\left(\mathrm{E}_{\text {used }} \text { tends to Maximum }\right)\end{array}$ \\
\hline $\begin{array}{l}\text { 2. The growth of «free energy of } \\
\text { living matter» (for the planet and } \\
\text { for each organism) }\end{array}$ & $\begin{array}{l}\text { 2. The growth of functional and energetic } \\
\text { activity of bio-structures; (low and } \\
\text { middle levels of bio-hierarchy of multi- } \\
\text { organism systems) }\end{array}$ & $\begin{array}{l}\text { 2. EPID - Energy Principle of } \\
\text { Intensive Development } \\
\left(\mathrm{E}_{\text {used }} / \text { Biomass tends to }\right. \\
\text { Maximum) }\end{array}$ \\
\hline $\begin{array}{l}\text { 3. «Acceleration of biogenic } \\
\text { migration of atoms» }\end{array}$ & $\begin{array}{l}\text { 3.Acceleration of biotic cycles of limiting } \\
\text { biogenic elements; (middle and upper } \\
\text { levels of bio-hierarchy) }\end{array}$ & $\begin{array}{l}\text { 3.MUC - Main Universal } \\
\text { Criterion. ( } \mathrm{E}_{\text {used }} / \text { Mass of } \\
\text { limiting biogenic element } \\
\text { tends to Maximum) }\end{array}$ \\
\hline
\end{tabular}

humanity must develop since our impacts on the global biosphere are becoming more and more powerful. With regret, we can add that his «Noosphere» is not the «Techno-biosphere» which we have now.

\section{References}

Allen J., Nelson M. (1989) Space Biospheres. Santa Fe, NM: Synergetic Press. 180 p.

Bartsev S.I. (2003) Systematic approach to LSS analyses and integration. Adv. Space Res. 31: 1823-1832.

Kovda V.A. (1975) Biogeochemical cycles in nature. Moscow: Nauka. 78 p.

Odum E.P. (1983) Basic ecology. Philadelphia: Saunders College Publishing. 368 p.

Pechurkin N.S. (1994) Biospherics: a new science. Life support and Biosphere Sci. 1: 85-88.

Pechurkin N.S. (2005) Quantitative criteria for the estimation of natural and artificial ecosystems functioning. Adv. Space Res. 35: 1507-1511.

Pechurkin N.S., Shirobokova I.M. (2001) System analysis of links interactions and development of ecosystems. Adv. Space Res. 27: 1497-1504.

Pechurkin N.S., Shirobokova I.M. (2003) Closed artificial ecosystems as a means of ecosystem studies for earth and space needs. Adv. Space Res. 31: 1667-1674.

Pechurkin N.S., Somova L.A. (2008) «Biospherics» approach for studies of natural and artificial ecosystems. Adv. Space Res. 41: 691-695.

Vernadsky V.I. (1926) Biosphere. Leningrad: Nauch-chim-tech. isd-vo, 136 p. (In Russian)

Vernadsky V.I. (1929) Biosphere. Paris: Alcan, T. XIII. 232 p. (In French)

Vernadsky V.I. (1986) Biosphere. London: Synergetic Press, 256 p. (In English)

Vernadsky V.I. (1989) Biosphere and Noosphere. Moskow: Nauka, 116 p. (In Russian)

Vernadsky V.I. (2004) Biosphere and Noosphere. M: Airis - Press, 576 p. (In Russian) 